\title{
Produção de forrageiras anuais de inverno em diferentes épocas de semeadura $^{1}$
}

\author{
Production of annual winter forages at different sowing times
}

\author{
Jussara Maria Ferrazza ${ }^{2}$, André Brugnara Soares ${ }^{3}$, Thomas Newton Martin ${ }^{4 *}$, Alceu Luiz Assmann e Vinicius $^{5}$ \\ Nicola $^{2}$
}

\begin{abstract}
RESUMO - O trabalho foi realizado com o objetivo de avaliar as características produtivas de forrageiras anuais de inverno (Avena strigosa Schereb, Lolium multiflorum Lam, Avena sativa, Triticum aestivum, Secale cereale e Triticosecale Wittmack) em quatro épocas de semeadura (11/3; 08/4; 06/5 e 03/6 de 2009). Foram avaliados o número de dias para o primeiro corte, o número de cortes, dias de utilização da pastagem, a densidade de plantas e perfilhos, a produção total, a matéria seca residual e a produção por corte. Houve interação significativa entre forrageiras e épocas de semeadura para todas as variáveis analisadas, o que possibilita alterar o planejamento forrageiro combinando cada forrageira dentro da melhor época de semeadura, direcionando a produção de forragem com o objetivo de suprir os vazios forrageiros. Uma das opções é a semeadura de aveia preta no início de março suprindo mais convenientemente as forragens no outono aos animais, em relação à sua semeadura em abril, mesmo que esta apresentasse uma produção total de forragem maior. Porém, se a maior necessidade de forragem é na primavera, a melhor combinação seria azevém semeado em junho. As aveias brancas, os azevéns, e a aveia preta IAPAR 61, são materiais com alta capacidade de produção e distribuição de forragem, especialmente se semeadas até início de maio.
\end{abstract}

Palavras-chave: Aveia. Plantas forrageiras. Semeadura.

\begin{abstract}
This study was carried out in order to evaluate the productive characteristics of annual winter forages (Avena strigosa Schereb, Lolium multiflorum Lam, Avena sativa, Triticum aestivum, Secale cereale and Triticosecale Wittmack), on four sowing dates (11 March, 8 April, 6 May and 3 June 2009). The work evaluated the number of days to first harvest, the number of harvests, days of pasture usage, plant and tiller density, total production, residual dry matter and production per harvest. There was significant interaction between forages and sowing dates for all the variables analysed, which makes possible altering forage planning, combining each forage type with its best sowing date and directing forage production in order to fill any gaps. One option is the sowing of oats at the beginning of March, more conveniently supplying fodder to animals in the autumn relative to its being sown in April, even though this represents greater total forage production. However, if the greatest need for forage is in the spring, the best combination would be ryegrass sown in June. White oats, ryegrass, and oats IAPAR 61, are materials which have a high capacity for fodder production and distribution, especially when sown by the beginning of May.
\end{abstract}

Key words: Oat. Forages. Sowing.

\footnotetext{
* Autor para correspondência

${ }^{1}$ Recebido para publicação em 01/08/2011; aprovado em 07/11/2012

Parte da Dissertação do primeiro autor

${ }^{2}$ Programa de Pós-Graduação em Agronomia da Universidade Tecnológica Federal do Paraná (Pato Branco), Via do Conhecimento, km 1 Pato Branco-PR, Brasil, 85.503-390, jussaraferrazza@yahoo.com.br, viniciusnicola@ hotmail.com

${ }^{3}$ Departamento de Agronomia, Universidade Tecnológica Federal do Paraná (Pato Branco), Via do Conhecimento, km 1, Pato Branco-PR, Brasil, 85.503-390, soares@utfpr.edu.br

${ }^{4}$ Departamento de Fitotecnia, Centro de Ciências Rurais, Universidade Federal de Santa Maria, Santa Maria-RS, Brasil, 97.105-900, martin. ufsm@gmail.com

${ }^{5}$ Instituto Agronômico do Paraná, Londrina-PR, Brasil, assmann@iapar.br
} 


\section{INTRODUÇÃO}

O cultivo de plantas forrageiras hibernais é favorável na região sul do Brasil. $\mathrm{O}$ crescimento ótimo de espécies de inverno ocorre em uma faixa de temperatura entre 18 e $23{ }^{\circ} \mathrm{C}$ e o aumento da taxa de acúmulo de massa seca dessas espécies hibernais tem alta correlação com o fotoperíodo (MORAES, 1995). O Estado do Paraná em especial, apresenta no período de inverno, temperaturas mínimas de $11^{\circ} \mathrm{C}$ e máximas de $19{ }^{\circ} \mathrm{C}$, favorecendo o estabelecimento dessas espécies na região (INSTITUTO AGRONÔMICO DO PARANÁ, 2009). Dessa forma, o Paraná possui condição para ampliar a utilização de forrageiras hibernais, fazendo com que estudos dessa natureza sejam necessários, além de que $80 \%$ da área cultivada no Estado com culturas anuais de verão permanecem em pousio no inverno, sendo somente $20 \%$ da área utilizado para cultivo nesse período com aveia, azevém, centeio, trigo, triticale entre outros (SÁ, 1995).

Atualmente, não apenas a produção total de forragem, mas também a distribuição de sua produção ao longo do tempo deve ser considerada, pois é o que define em grande parte o custo de produção pela maior ou menor necessidade de alimentar os animais com concentrado ou forragem conservada (COSTA et $a l ., 2008)$. As forrageiras anuais de inverno que vêm sendo utilizadas para suprir esta necessidade alimentar dos animais são principalmente o azevém, aveia preta e branca, centeio, triticale e trigo (NICOLOSO; LANZANOVA; LOVATO, 2006). No entanto, a cada ano são lançadas novas cultivares dessas espécies, que nem sempre vem acompanhadas de um conhecimento sobre sua dinâmica de produção de forragem, sobretudo se relacionado aos distintos ambientes e épocas de semeadura.

Devido aos avanços no melhoramento genético das diversas espécies forrageiras de inverno, e às variações climáticas ocorridas nos últimos anos, devem-se buscar novas informações a respeito do momento ideal de implantação destas forrageiras, produtividade, distribuição de produção ao longo do tempo, bem como seu valor nutritivo, sendo possível através destas informações indicar aos produtores qual a melhor forrageira para determinada época de semeadura e local. Desta forma, objetivou-se avaliar as características produtivas de forrageiras anuais de inverno em distintas épocas de semeaduras.

\section{MATERIAL E MÉTODOS}

O experimento foi conduzido no período de 11 de março a 30 de outubro de 2009, na área experimental do
Instituto Agronômico do Paraná, Pato Branco, situado na região fisiográfica denominada Terceiro Planalto Paranaense, com coordenadas $26^{\circ} 07^{\prime} \mathrm{S}$ e $52^{\circ} 41^{\prime} \mathrm{W}$, altitude de $700 \mathrm{~m}$. O clima da região é o subtropical úmido do tipo (Cfa), conforme classificação de Köppen (MAACK, 1968). A precipitação pluvial é de $1.800 \mathrm{~mm}$ distribuídos ao longo do ano. $\mathrm{O}$ solo predominante na área pertence a unidade de mapeamento LATOSSOLO VERMELHO distroférrico úmbrico (BHERING et al., 2008). A análise química revelou os seguintes valores: $\mathrm{PH}$ em $\mathrm{CaCl}=$ 5,1; M.O. $=40,21 \mathrm{gdm}^{-3} ; \mathrm{P}=13,44 \mathrm{mgdm}^{-3} ; \mathrm{K}=0,50$ $\mathrm{cmol}_{\mathrm{c}} \mathrm{dm}^{-3} ; \mathrm{Cu}=3,23 \mathrm{mgdm}^{-3} ; \mathrm{Fe}=26,03 \mathrm{mgdm}^{-3} ; \mathrm{Zn}=$ $1,64 \mathrm{mgdm}^{-3} ; \mathrm{MN}=0,00 \mathrm{mgdm}^{-3} ; \mathrm{Al}^{+3}=0,00 \mathrm{cmol} \mathrm{dm}^{-3}$; $\mathrm{H}+\mathrm{Al}=4,28 \mathrm{cmol}_{\mathrm{dm}}^{-3} ; \mathrm{Ca}=7,1 \mathrm{cmol} \mathrm{dm}^{-3} ; \mathrm{Mg}=3,1$ $\mathrm{cmol}_{\mathrm{c}} \mathrm{dm}^{-3} ; \mathrm{SB}=10,75 \mathrm{cmol}_{\mathrm{c}} \mathrm{dm}^{-3} ; \mathrm{V}=71,52 \%$. A área experimental estava sendo utilizada no sistema plantio direto, com rotação de soja e milho no verão e no inverno aveia como cobertura ou trigo para produção agrícola. Após a colheita da soja, realizou-se a adubação de acordo com as recomendações técnicas da Comissão de Química e Fertilizante do solo (2004). A adubação foi realizada concomitante à abertura dos sulcos por meio de uma semeadoura com espaçamento entre fileiras de $17 \mathrm{~cm}$, consistindo da adubação de base com $45 \mathrm{~kg} \mathrm{ha}^{-1}$ de $\mathrm{P}_{2} \mathrm{O}_{5}$. A adubação de cobertura constou de $100 \mathrm{~kg} \mathrm{ha}^{-1} \mathrm{de} \mathrm{N}$, na forma de uréia, parcelada em duas aplicações iguais distribuídas a lanço 30 e 60 dias após cada época de semeadura.

$\mathrm{O}$ delineamento experimental utilizado foi o de blocos ao acaso com três repetições em parcelas subdivididas, utilizando quatro épocas de semeadura (parcela) e dezesseis forrageiras (subparcelas). As semeaduras foram realizadas nas datas de: 11 de março, 08 de abril, 06 de maio e 03 de junho de 2009. As subparcelas foram compostas por 11 fileiras com três metros de comprimento, com área útil de seis metros quadrados, totalizando $1.600 \mathrm{~m}^{2}$.

As forrageiras e a quantidade de sementes utilizadas (número de sementes viáveis $\mathrm{m}^{-2}$ ) foram as seguintes: quatro cultivares de aveia branca (Avena sativa L.): FAPA 2 (350), FUNDACEP FAPA 43 (350), IPR 126 (250) e UTF Iguaçú densidade (350); seis cultivares de aveia preta (Avena strigosa Schreb): Aveia Preta Comum (350), UPF 21-Moreninha (400), Agro Planalto (300), Agro Coxilha (300), Agro Zebu (300) e IAPAR 61 (300); duas cultivares de azevém (Lolium multiflorum Lam.): Azevém Comum (350) e São Gabriel (350); uma cultivar de centeio (Secale cereale L.): Serrano (350); duas cultivares de triticale (X Triticosecale Wittmack): TCL 399 (350), POLO 981 (450) e um cultivar de trigo duplo-propósito BRS tarumã (Triticum aestivum L.) (350).

Dentre os tratos culturais realizou-se a aplicação de herbicida de folha larga à base de Metsulfuron - 
Metil $20 \%$ e, periodicamente era realizado o rouging (limpeza manual) das plantas daninhas nas fases iniciais de crescimento (de 2 a 4 folhas). Os cortes foram realizados quando a média de altura das plantas de todas as repetições atingia $30 \mathrm{~cm}$ para as aveias e triticales e $25 \mathrm{~cm}$ para os azevéns, centeio e trigo, correspondente a $95 \%$ de interceptação luminosa para essas espécies (SILVA; NASCIMENTO JÚNIOR, 2006). Todas as forrageiras foram cortadas a sete $\mathrm{cm}$ do nível do solo. Com o auxílio de um quadro de $0,4 \mathrm{~m}^{2}$ e de uma tesoura de corte, as amostras foram coletadas, identificadas, pesadas e colocadas em sacos de papel, secas em estufa de ventilação forçada a $60 \pm 5{ }^{\circ} \mathrm{C}$ até massa constante, posteriormente pesadas para a estimativa do percentual de matéria seca (MS). Subsequente aos cortes amostrais, por meio de uma roçadeira costal as parcelas foram uniformizadas na altura residual padronizada para cada cultivar.

As variáveis avaliadas foram: número de dias para o primeiro corte (NDPC, dias), número médio de cortes (NDC), número dias de utilização da pastagem (NDU, dias), número de plantas (NPL, plantas $\mathrm{m}^{-2}$ ), número de perfilhos (NPE, perfilhos $\mathrm{m}^{-2}$ ), produção total de matéria seca (PT, $\mathrm{kg} \mathrm{ha}^{-1}$ de MS), e matéria seca residual (MSR, $\left.\mathrm{kg} \mathrm{ha}^{-1} \mathrm{de} \mathrm{MS}\right)$, produção de forragem em oito cortes sequenciais, do primeiro (MSC1, $\mathrm{kg} \mathrm{ha}^{-1}$ de MS) ao oitavo corte (MSC8, $\mathrm{kg} \mathrm{ha}^{-1}$ de MS). O número de dias até o primeiro corte (NDPC) foi definido pelo somatório de dias entre a semeadura até a realização do primeiro corte. A média do número de cortes (NDC) foi obtida pela somatória de todos os cortes efetuados em cada forrageira nas distintas épocas de semeadura. $\mathrm{O}$ número de dias de utilização da pastagem (NDU) foi o resultado do somatório dos dias entre o primeiro corte até o último corte em cada forrageira nas diferentes épocas de semeadura em relação aos tratamentos. A contagem do número de plantas (NPL) foi feita 30 dias após a semeadura, em 60 centímetros da fileira, em dois pontos amostrais. Posteriormente, calculou-se o número médio de plantas $\mathrm{m}^{-2}$. A contagem do número de perfilhos (NPE) foi realizada no primeiro corte de cada forrageira, por intermédio de um quadro de $0,16 \mathrm{~m}^{2}$.

A produção total de forragem foi obtida a partir do somatório da produção em cada corte realizado nas 16 forrageiras para as distintas épocas de semeadura transformada em produção total de matéria seca $\left(\mathrm{kg} \mathrm{ha}^{-1} \mathrm{de}\right.$ MS). Amatéria seca residual (MRS) representa a quantidade de matéria seca remanescente no campo, que não entrou no cômputo da produção da PT. Essa variável foi avaliada em todas as parcelas, ao mesmo tempo, estimando a quantidade de palhada que ficaria para um sistema de plantio direto. Usou-se um quadro amostral de $0,4 \mathrm{~m}^{2}$, onde a matéria vegetal foi cortada rente ao solo, submetida a secagem à estufa $\left(60 \pm 5{ }^{\circ} \mathrm{C}\right.$ até massa constante $)$ e determinação da quantidade de palhada em $\mathrm{kg}$ MS/ha. Os resultados obtidos foram submetidos à análise de variância e as análises complementares por meio do teste de ScottKnott a 5\% de erro.

\section{RESULTADOS E DISCUSSÃO}

A partir dos resultados obtidos verificou-se que houve interação significativa $(p<0,05)$ entre as forrageiras e as épocas de semeadura para todas as variáveis avaliadas (Tabela 1).

Verificou-se que a terceira época de semeadura proporcionou um menor número de dias para o primeiro corte, seguidos da segunda, quarta e primeira época de semeadura (Tabela 2). Como o resultado das variáveis avaliadas NDPC, NDC e NDU apresentaram os mesmos valores para as três repetições (não possuindo variação para a mesma forrageira), não sendo possível realizar a análise de variância. Observou-se que quando semeadas antecipadamente, em 11 de março (época 1), as plantas foram expostas a condições com temperaturas elevadas, promovendo desenvolvimento inicial mais lento. Já quando semeadas em abril e maio, todas as forrageiras apresentaram um menor número de dias para o primeiro corte, estando de acordo com as indicações para a semeadura nesta região, segundo Flaresso, Gross e Almeida (2001).

Convém salientar que, na média das espécies, o primeiro corte na primeira época foi feito 12 dias antes do primeiro corte na segunda época, representando uma grande vantagem econômica e logística dentro dos sistemas reais de produção, amenizando o vazio forrageiro outonal. Desde que a terra esteja desocupada (depois da colheita do cultivo de verão) valeria a pena semear a pastagem antecipadamente, mesmo que o número de dias para o primeiro corte seja proporcionalmente maior à antecipação da semeadura. Obviamente que esse raciocínio deve também considerar as condições climáticas de cada região. Da segunda para terceira época houve somente quatro dias de atraso no NDPC, ou seja, antecipando 28 dias na semeadura, atrasar-se-iam somente quatro dias para o primeiro uso da pastagem. Neste caso fica evidente que, na média das cultivares, não seria vantajoso atrasar a semeadura para depois de 8 de abril, considerando-se a uniformidade no suprimento de forragem.

Em todas as épocas de semeadura, o azevém Comum e o São Gabriel foram as forrageiras que tiveram seu desenvolvimento mais lento até atingir o primeiro corte, seguido dos triticales e do trigo. De acordo com Nelson, 
Tabela 1 - Análise de variância (forrageiras de inverno x época de semeadura), com as respectivas fontes de variação (FV), graus de liberdade $(\mathrm{GL})$, quadrados médios $(\mathrm{QM})$, estatística $\mathrm{F}$ calculada $(\mathrm{F})$ e probabilidade $\alpha=\mathrm{P}(\mathrm{F} \geq \mathrm{Fc})$, para as variáveis número de plantas por metro quadrado (NPL), número de perfilhos por metro quadrado (NPE), matéria seca residual (MSR, e produção total de matéria seca (PT), matéria seca total em cada um dos oito cortes (MSC1), (MSC2), (MSC3), (MSC4), (MSC5), (MSC6), (MSC7) e (MSC8)

\begin{tabular}{|c|c|c|c|c|c|c|c|}
\hline \multirow{2}{*}{ FV } & \multirow{2}{*}{ GL } & \multicolumn{2}{|c|}{-----NPL (plantas m²)------ } & \multicolumn{2}{|c|}{-----NPE (perfilhos $\mathrm{m}^{-2}$ )----- } & \multicolumn{2}{|c|}{----MSR (kg de MS ha-1)---- } \\
\hline & & $\mathrm{QM}$ & $\mathrm{P}$ & $\mathrm{QM}$ & $\mathrm{F} \geq \mathrm{Fc}$ & $\mathrm{QM}$ & $\mathrm{P}$ \\
\hline Época(a) & 3 & 560865,35 & 0,00 & 2133042,07 & 0,00 & 771319,49 & 0,000 \\
\hline Forrageiras(d) & 15 & 154235,26 & 0,00 & 1536216,83 & 0,00 & 638955,35 & 0,000 \\
\hline $\mathrm{axd}$ & 45 & 15968,59 & 0,00 & 190765,945 & 0,00 & 388970,47 & 0,000 \\
\hline Erro & 126 & 3245,21 & & 16881,945 & & 68529,86 & \\
\hline Média & & 367,94 & & 1457,55 & & 1137,34 & \\
\hline \multirow[t]{2}{*}{$\mathrm{CV}^{*}$} & & 15,48 & & 8,91 & & 23,02 & \\
\hline & & \multicolumn{2}{|c|}{------PT (kg de MS ha-1)------ } & \multicolumn{2}{|c|}{---MSC1 (kg de MS ha-1)--- } & \multicolumn{2}{|c|}{---MSC2 (kg de MS ha-1)--- } \\
\hline Época(a) & 3 & 46642771,83 & 0,00 & 189021,01 & 0,008 & 747255,10 & 0,00 \\
\hline Forrageiras(d) & 15 & 22291810,73 & 0,00 & 240440,62 & 0,00 & 514114,77 & 0,00 \\
\hline $\mathrm{a} \times \mathrm{d}$ & 45 & 2405272,84 & 0,00 & 182903,68 & 0,00 & 250346,14 & 0,00 \\
\hline Erro & 126 & 258554,01 & & 45663,73 & & 26242,72 & \\
\hline Média & & 5935,33 & & 1216,27 & & 1190,29 & \\
\hline \multirow[t]{2}{*}{$\mathrm{CV}$} & & 8,57 & & 17,57 & & 13,61 & \\
\hline & & \multicolumn{2}{|c|}{----MSC3 (kg de MS ha-1)---- } & \multicolumn{2}{|c|}{---MSC4 (kg de MS ha'-1)--- } & \multicolumn{2}{|c|}{---MSC5 (kg de MS ha-1)--- } \\
\hline Época(a) & 3 & 1375383,61 & 0,00 & 114176,15 & 0,004 & 87297,58 & 0,02 \\
\hline Forrageiras(d) & 15 & 1010352,64 & 0,00 & 686086,60 & 0,00 & 616244,12 & 0,00 \\
\hline $\mathrm{axd}$ & 44 & 283843,46 & 0,00 & 110464,34 & 0,00 & 116190,83 & 0,00 \\
\hline Erro & 124 & 42144,63 & & 24314,70 & & 26468,94 & \\
\hline Média & & 1089,59 & & 865,24 & & 859,60 & \\
\hline \multirow[t]{2}{*}{$\mathrm{CV}$} & & 18,84 & & 18,02 & & 18,93 & \\
\hline & & \multicolumn{2}{|c|}{----MSC6 (kg de MS ha-1)---- } & \multicolumn{2}{|c|}{---MSC7 (kg de MS ha-1)--- } & \multicolumn{2}{|c|}{---MSC8 (kg de MS ha-1)--- } \\
\hline Época(a) & 3 & 383436,82 & 0,00 & 102112,84 & 0,056 & 30046,19 & 0,30 \\
\hline Forrageiras(d) & 15 & 392924,83 & 0,00 & 455612,62 & 0,00 & 232641,59 & 0,00 \\
\hline $\mathrm{axd}$ & 44 & 165470,25 & 0,00 & 151161,81 & 0,001 & 118012,64 & 0,043 \\
\hline Erro & 124 & 30759,30 & & 32746,58 & & 26258,89 & \\
\hline Média & & 935,73 & & 928,64 & & 876,26 & \\
\hline $\mathrm{CV}$ & & 18,74 & & 19,49 & & 18,49 & \\
\hline
\end{tabular}


Tabela 2 - Caracterização para os cortes e utilização das pastagens. Pato Branco, 2010

\begin{tabular}{|c|c|c|c|c|c|c|c|c|c|c|c|c|c|}
\hline \multirow{2}{*}{ Sigla } & \multirow{2}{*}{ Forrageiras/Épocas* } & \multicolumn{4}{|c|}{--------NDPC------- } & \multicolumn{4}{|c|}{ 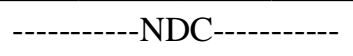 } & \multicolumn{4}{|c|}{-------------NDU------------ } \\
\hline & & 1 & 2 & 3 & 4 & 1 & 2 & 3 & 4 & 1 & 2 & 3 & 4 \\
\hline $\mathrm{AZC}$ & Az. Comum & 103 & 75 & 61 & 78 & 7 & 0 & 7 & 4 & 105 & 122 & 108 & 63 \\
\hline AZS & Az. São Gabriel & 103 & 75 & 61 & 69 & 8 & 8 & 7 & 5 & 122 & 122 & 108 & 72 \\
\hline $\mathrm{AB} 2$ & AB FAPA 2 & 62 & 50 & 55 & 61 & 7 & 6 & 5 & 4 & 132 & 147 & 83 & 80 \\
\hline AB43 & AB FAPA 43 & 62 & 56 & 55 & 61 & 6 & 5 & 5 & 3 & 132 & 110 & 101 & 42 \\
\hline ABI & AB IPR 126 & 71 & 62 & 61 & 69 & 8 & 7 & 6 & 4 & 154 & 135 & 95 & 72 \\
\hline $\mathrm{ABU}$ & AB UTF Iguaçú & 62 & 56 & 55 & 61 & 9 & 8 & 7 & 5 & 169 & 147 & 120 & 86 \\
\hline APC & AP Comum & 62 & 50 & 47 & 54 & 6 & 5 & 5 & 4 & 100 & 84 & 70 & 56 \\
\hline APM & AP Moreninha & 62 & 50 & 47 & 54 & 6 & 6 & 7 & 5 & 100 & 109 & 122 & 74 \\
\hline APP & AP Agro Planalto & 62 & 56 & 47 & 54 & 6 & 5 & 5 & 4 & 100 & 85 & 70 & 56 \\
\hline APC & AP Agro Coxilha & 62 & 56 & 47 & 54 & 6 & 6 & 5 & 4 & 100 & 103 & 70 & 56 \\
\hline APZ & AP Agro Zebu & 62 & 50 & 47 & 54 & 7 & 6 & 6 & 5 & 125 & 109 & 91 & 74 \\
\hline AP61 & AP IAPAR 61 & 62 & 50 & 55 & 61 & 7 & 8 & 6 & 5 & 163 & 153 & 120 & 86 \\
\hline CES & Centeio Serrano & 71 & 56 & 55 & 61 & 8 & 6 & 6 & 3 & 116 & 103 & 76 & 42 \\
\hline TBT & Trigo BRS Tarumã & 71 & 62 & 61 & 69 & 8 & 7 & 5 & 4 & 116 & 97 & 70 & 55 \\
\hline T399 & Triticale TCL 399 & 71 & 62 & 55 & 69 & 7 & 5 & 5 & 3 & 116 & 83 & 76 & 41 \\
\hline TPO & Triticale POLO 981 & 71 & 62 & 61 & 69 & 6 & 5 & 5 & 2 & 102 & 83 & 70 & 34 \\
\hline
\end{tabular}

*Épocas de semeadura: Época 1 = 11/03/2009; Época 2 = 08/04/2009; Época $3=06 / 05 / 2009 ;$ Época $4=03 / 06 / 2009 ;$ Az. = azevém; AB = aveia branca; AP = aveia preta. Número de dias para o primeiro corte (NDPC), número de cortes (NDC) e número de dias de utilização das pastagens (NDU), conforme as forrageiras e as épocas de semeadura

Phillips e Watson (1995) isso ocorre provavelmente por serem gramíneas que se desenvolvem favoravelmente em clima subtropical temperado. Verificou-se que o primeiro corte ocorreu 61 dias após a semeadura, sendo 10 dias mais atrasado em relação aos dados apresentados por Pereira $e t$ al. (2008), em semeaduras realizadas no início do mês de maio em regiões de clima subtropical úmido. Já as aveias pretas apresentaram um desenvolvimento inicial mais acelerado, podendo ser aproveitadas mais cedo, suprindo o vazio forrageiro de outono.

Flaresso, Gross e Almeida (2001), verificaram que, em semeaduras em março, abril, maio e junho (Vale do Itajaí, SC), o primeiro corte para azevém foi aos 114; 85; 94 e 80 dias após a semeadura, respectivamente, e para aveia preta foi aos 52; 51; 68 e 64 dias após a semeadura, respectivamente. Resultados experimentais para o azevém comum, no Rio Grande do Sul indicaram que quando a cultura foi semeada em abril, o número de dias até o primeiro corte foi de 124 dias (FLORES et al., 2008). Verificou-se que em semeaduras mais precoces houve um maior número de cortes, reduzindo-se em datas posteriores de semeadura (Tabela 2). Resultados similares foram obtidos por Flaresso, Gross e Almeida (2001), que semeando aveia preta comum e azevém comum em março e abril obtiveram maior número de cortes e maior período de utilização da pastagem que quando semeados em maio e junho. Considerando todas as cultivares, a média do número de cortes na primeira, segunda, terça e quarta épocas foram respectivamente 7; 6,3; 5,7 e 4 cortes, sendo que o maior número de cortes foi obtido pela aveia branca UTF Iguaçú na primeira época, e o menor pela triticale POLO 981 na quarta época de semeadura.

O atraso das épocas de semeadura ocasionou uma redução do período de utilização da pastagem (Tabela 2), devido provavelmente às diferenças de fotoperíodo e temperatura. Verificou-se que nas primeiras épocas, na fase intermediária de desenvolvimento estão expostas a temperaturas amenas e curto período de luminosidade, ao contrário do que é observado nas épocas subseqüentes sendo induzidas ao final do ciclo vegetativo. No mesmo sentido, Flaresso, Gross e Almeida (2001) obtiveram duração do período de utilização da pastagem variando de 122 dias, quando semeada em março, a 48 dias quando semeada em junho, concluindo que é interessante realizar a semeadura precocemente no mês de abril, tendo desta forma uma maior duração da pastagem, além de diminuir os vazios forrageiros e promover maior tempo de cobertura 
vegetal sob o solo. Observou-se que para todas as forrageiras a terceira época de semeadura foi a que proporcionou maior densidade de plantas, ao contrário do que foi observado na primeira época (Tabela 3).
A baixa densidade de plantas obtidas na primeira época provavelmente se deve às altas temperaturas ocorridas durante o mês de março, sendo este um fator desfavorável para a emergência e perfilhamento das

Tabela 3 - Média dos caracteres avaliados nas diferentes forrageiras e épocas de semeadura

\begin{tabular}{|c|c|c|c|c|c|c|c|c|}
\hline \multirow{2}{*}{$\begin{array}{c}\text { Forrageira } \\
\text { Épocas }\end{array}$} & \multicolumn{4}{|c|}{---------------------NPL ****-------------------- } & \multicolumn{4}{|c|}{ 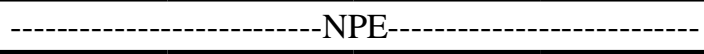 } \\
\hline & 1 & 2 & 3 & 4 & 1 & 2 & 3 & 4 \\
\hline $\mathrm{AZC}$ & $238 \mathrm{aC}^{* *}$ & $776 \mathrm{aA}$ & $836 \mathrm{aA}$ & $708 \mathrm{aB}$ & $1014 \mathrm{bD}$ & $2745 \mathrm{aB}$ & $3162 \mathrm{aA}$ & $2516 \mathrm{aC}$ \\
\hline AZS & $263 \mathrm{aB}$ & $726 \mathrm{aA}$ & $814 \mathrm{aA}$ & $752 \mathrm{aA}$ & $1465 \mathrm{aC}$ & $2556 \mathrm{aA}$ & $2354 \mathrm{bB}$ & $2631 \mathrm{aA}$ \\
\hline $\mathrm{AB} 2$ & $246 \mathrm{aB}$ & $342 \mathrm{bB}$ & 466 bA & $316 \mathrm{bB}$ & $911 \mathrm{bC}$ & $892 \mathrm{eC}$ & 1494 eA & $1172 \mathrm{cB}$ \\
\hline AB43 & $213 \mathrm{aC}$ & $393 \mathrm{bB}$ & $521 \mathrm{bA}$ & $348 \mathrm{bB}$ & 1194 bB & $1296 \mathrm{cB}$ & 1456 eA & $1448 \mathrm{cA}$ \\
\hline $\mathrm{ABI}$ & $125 \mathrm{aB}$ & $295 \mathrm{cA}$ & $292 \mathrm{dA}$ & $275 \mathrm{bA}$ & $1048 \mathrm{bB}$ & $1116 \mathrm{~dB}$ & $1364 \mathrm{eA}$ & $1331 \mathrm{cA}$ \\
\hline $\mathrm{ABU}$ & $242 \mathrm{aB}$ & $432 \mathrm{bA}$ & $491 \mathrm{bA}$ & $399 \mathrm{bA}$ & $1024 \mathrm{bC}$ & $1338 \mathrm{cB}$ & $1717 \mathrm{dA}$ & $1435 \mathrm{cB}$ \\
\hline APC & $223 \mathrm{aC}$ & $395 \mathrm{bB}$ & $523 \mathrm{bA}$ & $447 \mathrm{bB}$ & $1132 \mathrm{bA}$ & 1339 cA & $1286 \mathrm{eA}$ & $1410 \mathrm{cA}$ \\
\hline APM & $207 \mathrm{aB}$ & $315 \mathrm{cA}$ & $423 \mathrm{bA}$ & $360 \mathrm{bA}$ & $1190 \mathrm{bA}$ & $1416 \mathrm{cA}$ & 1282 eA & $1242 \mathrm{cA}$ \\
\hline APP & $245 \mathrm{aB}$ & $292 \mathrm{cB}$ & 384 cA & $346 \mathrm{bA}$ & $1304 \mathrm{aA}$ & $1328 \mathrm{cA}$ & 1389 eA & $1407 \mathrm{cA}$ \\
\hline APC & $209 \mathrm{aB}$ & $293 \mathrm{cB}$ & $454 \mathrm{bA}$ & $364 \mathrm{bA}$ & $1298 \mathrm{aA}$ & $1496 \mathrm{bA}$ & $1364 \mathrm{eA}$ & $1359 \mathrm{cA}$ \\
\hline APZ & $247 \mathrm{aB}$ & $299 \mathrm{cB}$ & $402 \mathrm{cA}$ & $378 \mathrm{bA}$ & $1158 \mathrm{bC}$ & $1229 \mathrm{dC}$ & $1407 \mathrm{eB}$ & $1639 \mathrm{bA}$ \\
\hline AP61 & $248 \mathrm{aB}$ & $349 \mathrm{bA}$ & $423 \mathrm{bA}$ & $360 \mathrm{bA}$ & 997 bC & $1296 \mathrm{cB}$ & 1574 eA & $1350 \mathrm{cB}$ \\
\hline CES & $170 \mathrm{aB}$ & $196 \mathrm{~dB}$ & $324 \mathrm{dA}$ & $301 \mathrm{bA}$ & $1338 \mathrm{aB}$ & $1684 \mathrm{bA}$ & $1733 \mathrm{dA}$ & $1707 \mathrm{bA}$ \\
\hline TBT & $228 \mathrm{aB}$ & $330 \mathrm{bA}$ & $400 \mathrm{cA}$ & $380 \mathrm{bA}$ & $1373 \mathrm{aC}$ & $1494 \mathrm{bC}$ & $2001 \mathrm{cA}$ & $1675 \mathrm{bB}$ \\
\hline T399 & $215 \mathrm{aC}$ & $214 \mathrm{dC}$ & $455 \mathrm{bA}$ & $330 \mathrm{bB}$ & $990 \mathrm{bB}$ & $1079 \mathrm{~dB}$ & $1393 \mathrm{eA}$ & $1394 \mathrm{cA}$ \\
\hline \multirow[t]{2}{*}{ TPO } & $221 \mathrm{aB}$ & $261 \mathrm{cB}$ & $457 \mathrm{bA}$ & $371 \mathrm{bA}$ & $1138 \mathrm{bA}$ & $1117 \mathrm{dA}$ & $1302 \mathrm{eA}$ & $1293 \mathrm{cA}$ \\
\hline & \multicolumn{4}{|c|}{ 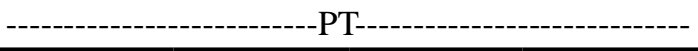 } & \multicolumn{4}{|c|}{ 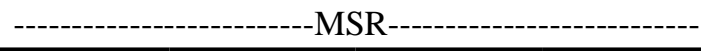 } \\
\hline $\mathrm{AZC}$ & $5985 \mathrm{cC}$ & $9545 \mathrm{aA}$ & $8698 \mathrm{aB}$ & $6536 \mathrm{aC}$ & $1874 \mathrm{aA}$ & $1502 \mathrm{aB}$ & $1269 \mathrm{cB}$ & $1273 \mathrm{bB}$ \\
\hline AZS & $9160 \mathrm{aA}$ & $8664 \mathrm{bA}$ & $8120 \mathrm{aA}$ & $5714 \mathrm{bB}$ & $1834 \mathrm{aA}$ & $1265 \mathrm{aB}$ & $1156 \mathrm{cB}$ & $1230 \mathrm{bB}$ \\
\hline $\mathrm{AB} 2$ & $7215 \mathrm{bA}$ & $7519 \mathrm{cA}$ & $5850 \mathrm{cB}$ & $5233 \mathrm{bB}$ & $1264 \mathrm{cB}$ & $757 \mathrm{bC}$ & $2030 \mathrm{bA}$ & $688 \mathrm{bC}$ \\
\hline AB43 & $8905 \mathrm{aA}$ & $7128 \mathrm{cB}$ & $7087 \mathrm{bB}$ & $4542 \mathrm{cC}$ & $1173 \mathrm{cA}$ & $1102 \mathrm{aA}$ & $934 \mathrm{dA}$ & $1411 \mathrm{aA}$ \\
\hline $\mathrm{ABI}$ & $9391 \mathrm{aA}$ & 8118 bB & $5696 \mathrm{cC}$ & $4321 \mathrm{cD}$ & $1056 \mathrm{cB}$ & 807 bB & $1523 \mathrm{cA}$ & $1209 \mathrm{bA}$ \\
\hline $\mathrm{ABU}$ & $9424 \mathrm{aA}$ & 8414 bB & $8179 \mathrm{aB}$ & $5678 \mathrm{bC}$ & $1179 \mathrm{cA}$ & $633 \mathrm{bB}$ & $1212 \mathrm{cA}$ & $965 \mathrm{bA}$ \\
\hline APC & $4952 \mathrm{dA}$ & $4021 \mathrm{eB}$ & $3885 \mathrm{~dB}$ & $3600 \mathrm{~dB}$ & $577 \mathrm{dA}$ & $1028 \mathrm{aA}$ & $909 \mathrm{dA}$ & $1016 \mathrm{bA}$ \\
\hline APM & $5097 \mathrm{~dB}$ & $4435 \mathrm{eB}$ & $5842 \mathrm{cA}$ & $4901 \mathrm{bB}$ & $1537 \mathrm{bA}$ & $1347 \mathrm{aA}$ & $652 \mathrm{~dB}$ & $1100 \mathrm{bA}$ \\
\hline APP & $4405 \mathrm{dA}$ & $3831 \mathrm{eA}$ & $3693 \mathrm{dA}$ & $3709 \mathrm{dA}$ & $1051 \mathrm{cA}$ & $558 \mathrm{bB}$ & $1218 \mathrm{cA}$ & $936 \mathrm{bA}$ \\
\hline APC & $4605 \mathrm{dA}$ & $4277 \mathrm{eA}$ & $3585 \mathrm{~dB}$ & $3732 \mathrm{~dB}$ & $1364 \mathrm{bB}$ & $565 \mathrm{bC}$ & $1862 \mathrm{bA}$ & $987 \mathrm{bC}$ \\
\hline APZ & $6001 \mathrm{cA}$ & $4111 \mathrm{eB}$ & $4446 \mathrm{~dB}$ & $4614 \mathrm{cB}$ & $777 \mathrm{~dB}$ & $1067 \mathrm{aB}$ & $1444 \mathrm{cA}$ & 819 bB \\
\hline AP61 & $8230 \mathrm{bA}$ & $7129 \mathrm{cB}$ & $7022 \mathrm{bB}$ & $5559 \mathrm{bC}$ & $1008 \mathrm{cA}$ & $819 \mathrm{bA}$ & $1129 \mathrm{cA}$ & $1051 \mathrm{bA}$ \\
\hline CES & $7724 \mathrm{bA}$ & $5882 \mathrm{~dB}$ & $5207 \mathrm{cB}$ & $4327 \mathrm{cC}$ & $1142 \mathrm{cC}$ & $1276 \mathrm{aC}$ & $2656 \mathrm{aA}$ & $1772 \mathrm{aB}$ \\
\hline TBT & $6736 \mathrm{cA}$ & $5981 \mathrm{dA}$ & $4393 \mathrm{~dB}$ & $4468 \mathrm{cB}$ & $596 \mathrm{dA}$ & $825 \mathrm{bA}$ & $822 \mathrm{dA}$ & $891 \mathrm{bA}$ \\
\hline T399 & $6413 \mathrm{cA}$ & $5900 \mathrm{dA}$ & $5606 \mathrm{cA}$ & 3744 B & $898 \mathrm{~dB}$ & $1001 \mathrm{aB}$ & $1028 \mathrm{~dB}$ & $1592 \mathrm{aA}$ \\
\hline TPO & $7268 \mathrm{bA}$ & $6470 \mathrm{cA}$ & $5270 \mathrm{cB}$ & $3667 \mathrm{dC}$ & $876 \mathrm{~dB}$ & $1006 \mathrm{aB}$ & $640 \mathrm{~dB}$ & $1596 \mathrm{aA}$ \\
\hline
\end{tabular}

*Épocas 1; 2; 3 e 4 =11/03/2009; 08/04/2009; 06/05/2009 e 03/06/2009, respectivamente; ** Médias seguidas pelas mesmas letras maiúsculas na horizontal e minúscula na vertical não diferem ao nível de $5 \%$ de erro pelo teste de Scott-Knott. ***Número de plantas por metro quadrado (NPL) e número de perfilhos por metro quadrado (NPE), produção total de matéria seca (PT, $\left.\mathrm{kg} \mathrm{ha}^{-1}\right)$, produção de forragem residual (MSR, $\mathrm{kg}^{-1}$ ) 
forrageiras de inverno. Na primeira época de semeadura não houve diferença significativa $(\mathrm{p}>0,05)$ entre as cultivares para a variável número de plantas por metro quadrado. $\mathrm{O}$ contrário ocorreu nas demais épocas, sendo que na segunda, terceira e quarta épocas os azevéns apresentaram o maior número de plantas. Semeando aveia preta Comum em maio, Rosseto e Nakagava (2001) encontraram uma média de 126 plantas por metro quadrado, valores inferiores aos obtidos neste trabalho. Já Pin et al. (2011) obtiveram populações iniciais de 496 e 400 plantas por metro quadrado, respectivamente para a aveia e azevém, quando semeadas em quatro de abril, concluindo que o mês de abril é a melhor época para a implantação destas culturas.

O número de perfilhos por metro quadrado para as aveias preta Comum, Moreninha, Agro Planalto, Agro Coxilha, e triticale POLO 981 não diferiu significativamente entre as épocas de semeadura (Tabela 3). No entanto, isso não foi verificado para as demais forrageiras as quais apresentaram maior perfilhamento na terceira e quarta época de semeadura. Observou-se que os azevéns apresentaram a maior densidade populacional de perfilho em todas as épocas de semeadura, o que ocorreu devido ao maior número de plantas por metro quadrado e a maior capacidade de perfilhamento desta espécie, manifestando vantagem na produção de forragem (Tabela 3). Segundo Vargas et al. (2006) entre populações de azevém comum existe alta variabilidade genética onde a produção de perfilhos variam entre 17,$44 ; 27,8$ e 39,9 por planta, fundamentais para a produção de forragem e cobertura do solo. Em trabalho realizado por Pin et al. (2011) e Rosseto e Nakagava (2001) obteve-se produções de 3 a 6 perfilhos por planta em aveia preta, os quais determinam a longevidade da forrageira, estando o presente trabalho de acordo com os resultados obtidos por eles.

Houve interação significativa $(\mathrm{p}<0,05)$ entre épocas de semeadura e forrageiras para produção total de matéria seca (PT). Essa informação está de acordo com Barbosa Neto et al. (2000), que verificaram interação significativa entre ambientes, cultivares e ciclo vegetativo de aveia branca, supondo que os índices de melhoramento e os resultados de produtividade obtidos estão intimamente relacionados aos efeitos de avaliação dos genótipos durantes vários anos e o meio em que foram cultivados. Observou-se que para a maioria das forrageiras as primeiras épocas de semeadura foram as que proporcionaram maior produção total de matéria seca, devido ao maior período vegetativo apresentado pelas plantas nestas épocas, indicando que atrasos na implantação das culturas acarretam em encurtamento do ciclo vegetativo, consequentemente perdas em produtividade (FLARESSO; GROSS; ALMEIDA, 2001).
O encurtamento do período de produção de forragem quando semeada tardiamente, acontece, além dos fatores ligados ao clima, devido às características de cada sistema de produção e planejamento de uso da terra. Considerando o sistema de integração lavoura-pecuária muito comum no sul do Brasil em que, por exemplo, o produtor planta soja no início de outubro, esse será o final do período de produção da pastagem, independente de sua condição e da data de semeadura. Alguns produtores dessecam a pastagem 10 a 20 dias antes da semeadura da cultura de verão, o que vem a diminuir mais ainda o tempo disponível para produção de forragem. Segundo a lei de VAN'T HOFF, a produção de forragem dobra a cada $10{ }^{\circ} \mathrm{C}$ de aumento na temperatura, sendo atribuído a isso o conceito da relação entre temperatura e taxa de desenvolvimento de uma planta, onde determinadas fases de desenvolvimento são antecipadas quando ocorrem aumentos progressivos de temperatura (FELÍCIO et al., 2001; FEROLLA et al., 2007), como pode ser observado neste trabalho.

Independente da época de semeadura observouse que as maiores produtividades foram obtidas pelos azevéns e aveias brancas, e as menores pelas aveias pretas. Sendo que a maior produção de forragem obtida foi pelo azevém comum na segunda época e a menor pela aveia preta Agro Coxilha na terceira época de semeadura. Flaresso, Gross e Almeida (2001) trabalhando com aveia preta e azevém, durante três anos consecutivos na estação experimental de Ituporanga (SC), com quatro épocas de semeadura de a março a junho, temperatura média de $15,7{ }^{\circ} \mathrm{C}$, obtiveram os melhores rendimentos e períodos de pastejo para as plantas semeadas em abril, resultando em maiores produções no mês de julho, estando de acordo com eles os resultados obtidos neste trabalho. Em contrapartida Ferolla et al. (2007), em estudo com aveia preta e triticale em três épocas de semeadura, abril, maio e junho, na região de Campos dos Goytacazes-RJ, de clima Aw, quente e úmido, com temperatura média de $24{ }^{\circ} \mathrm{C}$, concluíram que a melhor época de semeadura para triticale foi abril e para a aveia preta maio/junho.

Os genótipos de azevém apresentaram altas produções quando semeados no início de abril e maio, corroborando com os dados obtidos por Pereira et al. (2008), que, testando 30 populações de azevém (Valença, $\mathrm{RJ})$, semeados no início de maio, obtiveram produções entre 3.654 e $8.554 \mathrm{~kg} \mathrm{ha}^{-1}$ de MS, demonstrando a variabilidade dos genótipos e diferenças entre ambientes. Segundo pesquisa realizada em uma região de clima $\mathrm{Cfa}$, com diferentes forrageiras de inverno em três níveis de luminosidade, semeadas em abril, obteve produções de matéria seca a céu aberto de 8.191; $7.815 ; 5.147$ e $4.550 \mathrm{~kg} \mathrm{ha}^{-1}$ de MS, respectivamente para azevém, aveia-branca, trigo duplo-propósito e aveia preta (KIRCHNER et al., 2010), demonstrando o grande 
potencial de produção de azevém e aveia branca nesta região, similar aos resultados deste trabalho. Com relação à matéria seca residual (Tabela 3), observou-se uma grande amplitude entre os resultados, demonstrando a quantidade de matéria seca que ficaria sobre o solo para um futuro plantio direto. Isso provavelmente ocorreu pela influência do fotoperíodo, pois como as forrageiras respondem à soma térmica houve um encurtamento do ciclo, acarretando em menores números de cortes e consequentemente um maior número de perfilhos vivos que floresceram, promovendo um resíduo final maior. A mais alta produção de forragem residual foi obtida pelo centeio na terceira época de semeadura, e a menor produção pela aveia preta Agro Planalto na segunda época.

De acordo com Sodré Filho et al. (2004) devem ser adotados sistemas de rotação de culturas que deixem em média um resíduo de matéria seca $6.000 \mathrm{~kg} \mathrm{ha}^{-1} \mathrm{ano}^{-1}$ na superfície do solo, pois nestas condições, melhoram os atributos físicos e químicos do solo, evitam perdas de água por erosão e evaporação, promovendo absorção da água e de nutrientes armazenados no perfil do solo. Independente do corte observou-se que para a maioria das forrageiras a segunda e a terceira época de semeadura foram as que proporcionaram maiores produções de forragem por corte (Tabela 4 e Tabela 5). As maiores produtividades foram obtidas pelas aveias brancas, pelos azevéns e pela aveia preta IAPAR 61. Trabalhos realizados na estação experimental da Embrapa Passo Fundo por Fontaneli et al. (2009) encontraram produções ao primeiro corte de 1.051 e $570 \mathrm{~kg} \mathrm{ha}^{-1}$ de MS respectivamente para centeio Serrano e aveia preta Agro Zebu, quando semeados em abril. Segundo Flores et al. (2008), avaliando diversos germoplasmas de azevém semeados em abril, obtiveram produções ao primeiro corte variando de 374 a $1.101 \mathrm{~kg} \mathrm{ha}^{-1}$ de MS, sendo o azevém comum o mais produtivo, estando os resultados deste trabalho de acordo com o trabalho dos referidos autores.

A baixa produtividade obtida pelas aveias pretas, exceto para a aveia IAPAR 61, é devido ao seu ciclo precoce e pelas características morfológicas, por possuir porte mais ereto e apresentarem um dossel forrageiro menos denso que as aveias brancas. Observa-se que na quarta época de semeadura a maior produtividade ao primeiro corte foi alcançada pelo azevém Comum, que produziu $126 \%$ a mais que o centeio Serrano, o qual foi o menos produtivo, ao contrário do que foi observado na primeira época de semeadura. Isto se deve provavelmente pelo azevém ser uma cultura de ciclo mais tardio, o qual tem pico de produções no mês de agosto/setembro, ao contrário do centeio que é de ciclo precoce e pico de produção em maio/junho (FLARESSO; GROSS; ALMEIDA, 2001).

Tabela 4 - Produção de forragem (kg MS/ha) do primeiro ao quarto corte para as forrageiras nas épocas de semeadura. Pato Branco, 2010

\begin{tabular}{|c|c|c|c|c|c|c|c|c|}
\hline \multirow{2}{*}{$\begin{array}{c}\text { Forrageira } \\
\text { Épocas }\end{array}$} & \multicolumn{4}{|c|}{ - } & \multicolumn{4}{|c|}{ 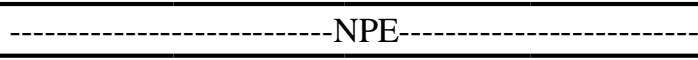 } \\
\hline & 1 & 2 & 3 & 4 & 1 & 2 & 3 & 4 \\
\hline AZC & $238 \mathrm{aC}^{* *}$ & $776 \mathrm{aA}$ & $836 \mathrm{aA}$ & $708 \mathrm{aB}$ & $1014 \mathrm{bD}$ & $2745 \mathrm{aB}$ & $3162 \mathrm{aA}$ & $2516 \mathrm{aC}$ \\
\hline AZS & $263 \mathrm{aB}$ & $726 \mathrm{aA}$ & $814 \mathrm{aA}$ & $752 \mathrm{aA}$ & $1465 \mathrm{aC}$ & $2556 \mathrm{aA}$ & $2354 \mathrm{bB}$ & $2631 \mathrm{aA}$ \\
\hline $\mathrm{AB} 2$ & $246 \mathrm{aB}$ & $342 \mathrm{bB}$ & $466 \mathrm{bA}$ & $316 \mathrm{bB}$ & $911 \mathrm{bC}$ & $892 \mathrm{eC}$ & $1494 \mathrm{eA}$ & $1172 \mathrm{cB}$ \\
\hline AB43 & $213 \mathrm{aC}$ & $393 \mathrm{bB}$ & $521 \mathrm{bA}$ & $348 \mathrm{bB}$ & $1194 \mathrm{bB}$ & $1296 \mathrm{cB}$ & $1456 \mathrm{eA}$ & $1448 \mathrm{cA}$ \\
\hline ABI & $125 \mathrm{aB}$ & $295 \mathrm{cA}$ & $292 \mathrm{dA}$ & $275 \mathrm{bA}$ & $1048 \mathrm{bB}$ & $1116 \mathrm{~dB}$ & $1364 \mathrm{eA}$ & $1331 \mathrm{cA}$ \\
\hline $\mathrm{ABU}$ & $242 \mathrm{aB}$ & $432 \mathrm{bA}$ & $491 \mathrm{bA}$ & $399 \mathrm{bA}$ & $1024 \mathrm{bC}$ & $1338 \mathrm{cB}$ & $1717 \mathrm{dA}$ & $1435 \mathrm{cB}$ \\
\hline APC & $223 \mathrm{aC}$ & $395 \mathrm{bB}$ & $523 \mathrm{bA}$ & $447 \mathrm{bB}$ & $1132 \mathrm{bA}$ & $1339 \mathrm{cA}$ & $1286 \mathrm{eA}$ & $1410 \mathrm{cA}$ \\
\hline APM & $207 \mathrm{aB}$ & $315 \mathrm{cA}$ & $423 \mathrm{bA}$ & $360 \mathrm{bA}$ & $1190 \mathrm{bA}$ & $1416 \mathrm{cA}$ & $1282 \mathrm{eA}$ & $1242 \mathrm{cA}$ \\
\hline APP & $245 \mathrm{aB}$ & $292 \mathrm{cB}$ & $384 \mathrm{cA}$ & $346 \mathrm{bA}$ & $1304 \mathrm{aA}$ & $1328 \mathrm{cA}$ & $1389 \mathrm{eA}$ & $1407 \mathrm{cA}$ \\
\hline APC & $209 \mathrm{aB}$ & $293 \mathrm{cB}$ & $454 \mathrm{bA}$ & $364 \mathrm{bA}$ & $1298 \mathrm{aA}$ & $1496 \mathrm{bA}$ & $1364 \mathrm{eA}$ & $1359 \mathrm{cA}$ \\
\hline APZ & $247 \mathrm{aB}$ & $299 \mathrm{cB}$ & $402 \mathrm{cA}$ & $378 \mathrm{bA}$ & $1158 \mathrm{bC}$ & $1229 \mathrm{dC}$ & $1407 \mathrm{eB}$ & $1639 \mathrm{bA}$ \\
\hline AP61 & $248 \mathrm{aB}$ & $349 \mathrm{bA}$ & $423 \mathrm{bA}$ & $360 \mathrm{bA}$ & $997 \mathrm{bC}$ & $1296 \mathrm{cB}$ & $1574 \mathrm{eA}$ & $1350 \mathrm{cB}$ \\
\hline CES & $170 \mathrm{aB}$ & $196 \mathrm{~dB}$ & $324 \mathrm{dA}$ & $301 \mathrm{bA}$ & $1338 \mathrm{aB}$ & $1684 \mathrm{bA}$ & $1733 \mathrm{dA}$ & $1707 \mathrm{bA}$ \\
\hline TBT & $228 \mathrm{aB}$ & $330 \mathrm{bA}$ & $400 \mathrm{cA}$ & $380 \mathrm{bA}$ & $1373 \mathrm{aC}$ & $1494 \mathrm{bC}$ & $2001 \mathrm{cA}$ & $1675 \mathrm{bB}$ \\
\hline T399 & $215 \mathrm{aC}$ & $214 \mathrm{dC}$ & $455 \mathrm{bA}$ & $330 \mathrm{bB}$ & $990 \mathrm{bB}$ & $1079 \mathrm{~dB}$ & $1393 \mathrm{eA}$ & $1394 \mathrm{cA}$ \\
\hline TPO & $221 \mathrm{aB}$ & $261 \mathrm{cB}$ & $457 \mathrm{bA}$ & $371 \mathrm{bA}$ & $1138 \mathrm{bA}$ & $1117 \mathrm{dA}$ & $1302 \mathrm{eA}$ & $1293 \mathrm{cA}$ \\
\hline
\end{tabular}


Continuação - Tabela 4

\begin{tabular}{|c|c|c|c|c|c|c|c|c|}
\hline \multirow[b]{2}{*}{ AZC } & \multicolumn{4}{|c|}{ 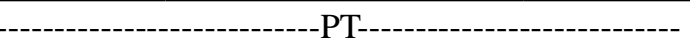 } & \multicolumn{4}{|c|}{ - } \\
\hline & $5985 \mathrm{cC}$ & $9545 \mathrm{aA}$ & $8698 \mathrm{aB}$ & $6536 \mathrm{aC}$ & $1874 \mathrm{aA}$ & $1502 \mathrm{aB}$ & $1269 \mathrm{cB}$ & $1273 \mathrm{bB}$ \\
\hline AZS & $9160 \mathrm{aA}$ & $8664 \mathrm{bA}$ & 8120 aA & $5714 \mathrm{bB}$ & $1834 \mathrm{aA}$ & $1265 \mathrm{aB}$ & $1156 \mathrm{cB}$ & $1230 \mathrm{bB}$ \\
\hline AB2 & $7215 \mathrm{bA}$ & $7519 \mathrm{cA}$ & $5850 \mathrm{cB}$ & $5233 \mathrm{bB}$ & $1264 \mathrm{cB}$ & $757 \mathrm{bC}$ & $2030 \mathrm{bA}$ & $688 \mathrm{bC}$ \\
\hline AB43 & $8905 \mathrm{aA}$ & $7128 \mathrm{cB}$ & $7087 \mathrm{bB}$ & $4542 \mathrm{cC}$ & $1173 \mathrm{cA}$ & $1102 \mathrm{aA}$ & $934 \mathrm{dA}$ & $1411 \mathrm{aA}$ \\
\hline ABI & $9391 \mathrm{aA}$ & $8118 \mathrm{bB}$ & 5696 cC & $4321 \mathrm{cD}$ & $1056 \mathrm{cB}$ & $807 \mathrm{bB}$ & $1523 \mathrm{cA}$ & $1209 \mathrm{bA}$ \\
\hline $\mathrm{ABU}$ & $9424 \mathrm{aA}$ & $8414 \mathrm{bB}$ & $8179 \mathrm{aB}$ & $5678 \mathrm{bC}$ & $1179 \mathrm{cA}$ & $633 \mathrm{bB}$ & $1212 \mathrm{cA}$ & $965 \mathrm{bA}$ \\
\hline APC & $4952 \mathrm{dA}$ & $4021 \mathrm{eB}$ & $3885 \mathrm{~dB}$ & $3600 \mathrm{~dB}$ & $577 \mathrm{dA}$ & $1028 \mathrm{aA}$ & $909 \mathrm{dA}$ & 1016 bA \\
\hline APM & $5097 \mathrm{~dB}$ & $4435 \mathrm{eB}$ & $5842 \mathrm{cA}$ & $4901 \mathrm{bB}$ & $1537 \mathrm{bA}$ & $1347 \mathrm{aA}$ & $652 \mathrm{~dB}$ & $1100 \mathrm{bA}$ \\
\hline APP & $4405 \mathrm{dA}$ & $3831 \mathrm{eA}$ & $3693 \mathrm{dA}$ & $3709 \mathrm{dA}$ & $1051 \mathrm{cA}$ & $558 \mathrm{bB}$ & $1218 \mathrm{cA}$ & $936 \mathrm{bA}$ \\
\hline APC & $4605 \mathrm{dA}$ & $4277 \mathrm{eA}$ & $3585 \mathrm{~dB}$ & $3732 \mathrm{~dB}$ & $1364 \mathrm{bB}$ & $565 \mathrm{bC}$ & $1862 \mathrm{bA}$ & $987 \mathrm{bC}$ \\
\hline APZ & $6001 \mathrm{cA}$ & $4111 \mathrm{eB}$ & $4446 \mathrm{~dB}$ & $4614 \mathrm{cB}$ & $777 \mathrm{~dB}$ & $1067 \mathrm{aB}$ & $1444 \mathrm{cA}$ & 819 bB \\
\hline AP61 & $8230 \mathrm{bA}$ & $7129 \mathrm{cB}$ & $7022 \mathrm{bB}$ & $5559 \mathrm{bC}$ & $1008 \mathrm{cA}$ & $819 \mathrm{bA}$ & $1129 \mathrm{cA}$ & $1051 \mathrm{bA}$ \\
\hline CES & $7724 \mathrm{bA}$ & $5882 \mathrm{~dB}$ & $5207 \mathrm{cB}$ & $4327 \mathrm{cC}$ & $1142 \mathrm{cC}$ & $1276 \mathrm{aC}$ & $2656 \mathrm{aA}$ & $1772 \mathrm{aB}$ \\
\hline TBT & $6736 \mathrm{cA}$ & $5981 \mathrm{dA}$ & $4393 \mathrm{~dB}$ & $4468 \mathrm{cB}$ & $596 \mathrm{dA}$ & $825 \mathrm{bA}$ & $822 \mathrm{dA}$ & 891 bA \\
\hline T399 & $6413 \mathrm{cA}$ & $5900 \mathrm{dA}$ & $5606 \mathrm{cA}$ & 3744 B & $898 \mathrm{~dB}$ & $1001 \mathrm{aB}$ & $1028 \mathrm{~dB}$ & $1592 \mathrm{aA}$ \\
\hline TPO & $7268 \mathrm{bA}$ & $6470 \mathrm{cA}$ & $5270 \mathrm{cB}$ & $3667 \mathrm{dC}$ & $876 \mathrm{~dB}$ & $1006 \mathrm{aB}$ & $640 \mathrm{~d} B$ & $1596 \mathrm{aA}$ \\
\hline
\end{tabular}

*Época 1 = 11/03/2009; Época 2 = 08/04/2009; Época 3 =06/05/2009; Época 4 =03/06/2009; Az. = azevém; AB = aveia branca; AP = aveia preta. **Médias seguidas pelas mesmas letras maiúsculas na horizontal e minúscula na vertical não diferem ao nível de 5\% de erro pelo teste de Scott-Knott.

***Produção de forragem no primeiro corte (MSC1, $\mathrm{kg} \mathrm{ha}^{-1}$ ), produção de forragem no segundo corte (MSC2, $\mathrm{kg} \mathrm{ha}^{-1}$ de MS), produção de forragem no terceiro corte (MSC3, $\mathrm{kg} \mathrm{ha}^{-1}$ ) e produção de forragem no quarto corte (MSC4, $\mathrm{kg} \mathrm{ha}^{-1}$ )

Tabela 5 - Média para a produção de forragem do quinto ao oitavo corte, conforme as forrageiras e as épocas de semeadura. Pato Branco, 2010

\begin{tabular}{|c|c|c|c|c|c|c|c|c|}
\hline \multirow{2}{*}{$\begin{array}{c}\text { Forrageiras } \\
\text { Época }\end{array}$} & \multicolumn{4}{|c|}{ 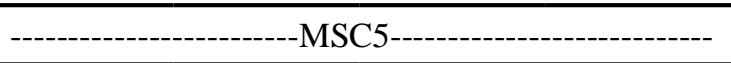 } & \multicolumn{4}{|c|}{--1 } \\
\hline & 1 & 2 & 3 & 4 & 1 & 2 & 3 & 4 \\
\hline $\mathrm{AZC}$ & $1252 \mathrm{bA}$ & $1299 \mathrm{aA}$ & $1242 \mathrm{aA}$ & $0 \mathrm{cB}$ & $964 \mathrm{cB}$ & $926 \mathrm{bB}$ & $1309 \mathrm{aA}$ & - \\
\hline AZS & $735 \mathrm{~dB}$ & $1041 \mathrm{bA}$ & $969 \mathrm{aA}$ & $1129 \mathrm{aA}$ & $1623 \mathrm{aA}$ & $1155 \mathrm{aB}$ & $1221 \mathrm{aB}$ & - \\
\hline $\mathrm{AB} 2$ & $1322 \mathrm{bA}$ & $1264 \mathrm{aA}$ & $1084 \mathrm{aA}$ & $0 \mathrm{cB}$ & $753 \mathrm{cB}$ & $1176 \mathrm{aA}$ & $0 \mathrm{dC}$ & - \\
\hline AB43 & $1625 \mathrm{aA}$ & $1455 \mathrm{aA}$ & $767 \mathrm{bB}$ & $0 \mathrm{cC}$ & $1555 \mathrm{aA}$ & $0 \mathrm{~dB}$ & $0 \mathrm{~dB}$ & - \\
\hline $\mathrm{ABI}$ & $1024 \mathrm{cA}$ & $958 \mathrm{bA}$ & $665 \mathrm{bB}$ & $0 \mathrm{cC}$ & $672 \mathrm{cA}$ & $532 \mathrm{cA}$ & $800 \mathrm{bA}$ & - \\
\hline $\mathrm{ABU}$ & $1012 \mathrm{cA}$ & $1256 \mathrm{aA}$ & $1068 \mathrm{aA}$ & $570 \mathrm{bB}$ & $1200 \mathrm{bA}$ & $1361 \mathrm{aA}$ & $1161 \mathrm{aA}$ & - \\
\hline APC & $484 \mathrm{dA}$ & $584 \mathrm{cA}$ & $701 \mathrm{bA}$ & $0 \mathrm{cB}$ & $1129 \mathrm{bA}$ & $0 \mathrm{~dB}$ & $0 \mathrm{~dB}$ & - \\
\hline APM & $654 \mathrm{dA}$ & $693 \mathrm{cA}$ & $818 \mathrm{bA}$ & $810 \mathrm{bA}$ & $1216 \mathrm{bA}$ & $660 \mathrm{cB}$ & $642 \mathrm{bB}$ & - \\
\hline APP & $472 \mathrm{dA}$ & $452 \mathrm{cA}$ & $622 \mathrm{bA}$ & $0 \mathrm{cB}$ & $1100 \mathrm{bA}$ & $0 \mathrm{~dB}$ & $0 \mathrm{~dB}$ & - \\
\hline APC & $418 \mathrm{dA}$ & $484 \mathrm{cA}$ & $513 \mathrm{bA}$ & $0 \mathrm{cB}$ & $816 \mathrm{cA}$ & $743 \mathrm{cA}$ & $0 \mathrm{~dB}$ & - \\
\hline APZ & $477 \mathrm{~dB}$ & $409 \mathrm{cB}$ & $813 \mathrm{bA}$ & $703 \mathrm{bA}$ & $1164 \mathrm{bA}$ & $593 \mathrm{cB}$ & $412 \mathrm{cB}$ & - \\
\hline AP61 & $1007 \mathrm{cA}$ & $1098 \mathrm{bA}$ & $1147 \mathrm{aA}$ & $667 \mathrm{bB}$ & $1218 \mathrm{bA}$ & $685 \mathrm{cB}$ & $720 \mathrm{bB}$ & - \\
\hline CES & $667 \mathrm{~dB}$ & $1034 \mathrm{bA}$ & $721 \mathrm{bB}$ & $0 \mathrm{cC}$ & $870 \mathrm{cA}$ & $1003 \mathrm{bA}$ & $587 \mathrm{bB}$ & - \\
\hline TBT & $573 \mathrm{dA}$ & $636 \mathrm{cA}$ & $781 \mathrm{bA}$ & $0 \mathrm{cB}$ & $593 \mathrm{cA}$ & $602 \mathrm{cA}$ & $0 \mathrm{~dB}$ & - \\
\hline T399 & $568 \mathrm{~dB}$ & 963 bA & $1026 \mathrm{aA}$ & $0 \mathrm{cC}$ & $807 \mathrm{cA}$ & $0 \mathrm{~dB}$ & $0 \mathrm{~dB}$ & - \\
\hline TPO & $1021 \mathrm{cA}$ & $923 \mathrm{bA}$ & $883 \mathrm{bA}$ & $0 \mathrm{cB}$ & $781 \mathrm{cA}$ & $0 \mathrm{~dB}$ & $0 \mathrm{~dB}$ & - \\
\hline
\end{tabular}


Continuação - Tabela 5

\begin{tabular}{|c|c|c|c|c|c|c|c|c|}
\hline \multirow[b]{2}{*}{$\mathrm{AZC}$} & \multicolumn{4}{|c|}{ 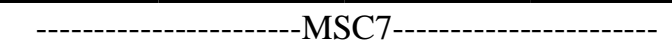 } & \multicolumn{4}{|c|}{ 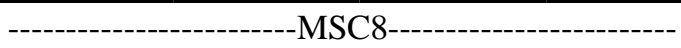 } \\
\hline & $1005 \mathrm{cB}$ & $1411 \mathrm{aA}$ & $1318 \mathrm{aA}$ & - & $0 \mathrm{~dB}$ & $1086 \mathrm{aA}$ & - & - \\
\hline AZS & 1304 bA & $1012 \mathrm{bB}$ & $1204 \mathrm{aA}$ & - & $1155 \mathrm{aA}$ & $1097 \mathrm{aA}$ & - & - \\
\hline $\mathrm{AB} 2$ & $629 \mathrm{dA}$ & $0 \mathrm{~dB}$ & $0 \mathrm{cB}$ & - & $0 \mathrm{dA}$ & $0 \mathrm{cA}$ & - & - \\
\hline AB43 & $0 \mathrm{eA}$ & $0 \mathrm{dA}$ & $0 \mathrm{cA}$ & - & $0 \mathrm{dA}$ & $0 \mathrm{cA}$ & - & - \\
\hline $\mathrm{ABI}$ & $587 \mathrm{~dB}$ & $841 \mathrm{bA}$ & $0 \mathrm{cC}$ & - & 906 bA & $0 \mathrm{cB}$ & - & - \\
\hline ABU & 899 cA & $917 \mathrm{bA}$ & $689 \mathrm{bB}$ & - & $836 \mathrm{bA}$ & $436 \mathrm{bB}$ & - & - \\
\hline APC & $0 \mathrm{eA}$ & $0 \mathrm{dA}$ & $0 \mathrm{cA}$ & - & $0 \mathrm{dA}$ & $0 \mathrm{cA}$ & - & - \\
\hline APM & $0 \mathrm{eB}$ & $0 \mathrm{~dB}$ & $865 \mathrm{bA}$ & - & $0 \mathrm{dA}$ & $0 \mathrm{cA}$ & - & - \\
\hline APP & $0 \mathrm{eA}$ & $0 \mathrm{dA}$ & $0 \mathrm{cA}$ & - & $0 \mathrm{dA}$ & $0 \mathrm{cA}$ & - & - \\
\hline APC & $0 \mathrm{eA}$ & $0 \mathrm{dA}$ & $0 \mathrm{cA}$ & - & $0 \mathrm{dA}$ & $0 \mathrm{cA}$ & - & - \\
\hline APZ & $805 \mathrm{cA}$ & $0 \mathrm{~dB}$ & $0 \mathrm{cB}$ & - & $0 \mathrm{dA}$ & $0 \mathrm{cA}$ & - & - \\
\hline AP61 & $1585 \mathrm{aA}$ & $1062 \mathrm{bB}$ & $0 \mathrm{cC}$ & - & $0 \mathrm{~dB}$ & $504 \mathrm{bA}$ & - & - \\
\hline CES & $841 \mathrm{cA}$ & $0 \mathrm{~dB}$ & $0 \mathrm{cB}$ & - & $1052 \mathrm{aA}$ & $0 \mathrm{cB}$ & - & - \\
\hline TBT & $577 \mathrm{dA}$ & $404 \mathrm{cA}$ & $0 \mathrm{cB}$ & - & $581 \mathrm{cA}$ & $0 \mathrm{cB}$ & - & - \\
\hline T399 & $565 \mathrm{dA}$ & $0 \mathrm{~dB}$ & $0 \mathrm{cB}$ & - & $0 \mathrm{dA}$ & $0 \mathrm{cA}$ & - & - \\
\hline TPO & $0, \mathrm{eA}$ & $0 \mathrm{dA}$ & $0 \mathrm{cA}$ & - & $0 \mathrm{dA}$ & $0 \mathrm{cA}$ & - & - \\
\hline Média & 928,64 & & & & 876,26 & & & \\
\hline $\mathrm{CV}(\%)$ & 19,49 & & & & 18,49 & & & \\
\hline
\end{tabular}

*Época 1 = 11/03/2009; Época 2 = 08/04/2009; Época 3 =06/05/2009; Época 4 =03/06/2009; Az. = azevém; AB = aveia branca; AP = aveia preta. **Médias seguidas pelas mesmas letras maiúsculas na horizontal e minúscula na vertical não diferem a 5\% de probabilidade de erro pelo teste de ScottKnott. *** Produção de forragem no quinto corte (MSC5, $\mathrm{kg} \mathrm{ha}^{-1}$ ), produção de forragem no sexto corte (MSC6 kg ha ${ }^{-1}$ ), produção de forragem no sétimo corte (MSC7, $\mathrm{kg} \mathrm{ha}^{-1}$ ) e produção de forragem no oitavo corte (MSC8, $\mathrm{kg} \mathrm{ha}^{-1}$ )

Para os triticales, observou-se que semeaduras antecipadas proporcionaram maiores produções de forragem e período vegetativo, sendo que para o triticale POLO 981 obtiveram-se somente dois cortes quando semeado em junho, o que acarretou em menores produções, indicando que semeaduras mais tardias para esta espécie acarreta em encurtamento do ciclo vegetativo.

Pode-se observar que semeaduras intermediárias foram as que proporcionaram maior período vegetativo, permitindo obter até oito cortes em algumas forrageiras, sendo ótimas opções para o vazio forrageiro de primavera. Observa-se que das forrageiras que permitiram sete cortes (Tabela 2 e 5), a mais produtiva foi a aveia preta IAPAR 61, quando semeada em março, e a menos produtiva foi o Trigo BRS Tarumã quando semeado em abril. Somente algumas forrageiras atingiram o oitavo corte, o que ocorreu devido ao maior período vegetativo apresentado por estas forrageiras quando semeadas mais cedo (março e abril). Dentre elas observou-se que a mais produtiva foi o azevém São Gabriel na primeira época, e a menos produtiva a aveia branca UTF Iguaçú na segunda época de semeadura.

\section{CONCLUSÕES}

1. As épocas de semeadura interferem nas características produtivas das forrageiras anuais de inverno, uma vez que semeaduras mais precoces promovem maiores produções de forragem e duração do ciclo vegetativo e semeaduras mais tardias, maiores densidade de plantas e perfilhos;

2. Os azevéns, as aveias brancas e a aveia preta IAPAR 61 são excelentes alternativas para o forrageamento de outono e inverno, por apresentarem longevidade de ciclo e altas produções de forragem, principalmente quando semeadas precocemente.

\section{REFERÊNCIAS}

BARBOSA NETO, J. F. B. et al. Progresso genético no melhoramento da aveia branca no Sul do Brasil. Pesquisa Agropecuária Brasileira, v. 35, n. 8, p. 1605-1612, 2000.

BHERING, S. B. et al. Mapa de solos do Estado do Paraná: legenda atualizada. Rio de Janeiro: EMBRAPA/IAPAR, 2008. 74 p 
COMISSÃO DE QUÍMICA E FERTILIDADE DO SOLO. Manual de adubação e calagem para os Estados do Rio Grande do Sul e Santa Catarina. 10 ed. Porto Alegre, SBCS 2004. 400 p.

COSTA, C. et al. Alternativas para contornar a estacionalidade de produção de forragens. Veterinária e Zootecnia, v. 15, n. 2, p. 193-203, 2008.

FELÍCIO, J. C. et al. Avaliação de genótipos de triticale e trigo em ambientes favoráveis e desfavoráveis no Estado de São Paulo. Bragantia, v. 60, n. 2, p. 83-91, 2001.

FEROLLA, S. F. et al. Produção de forragem, composição da massa de forragem e relação lâmina foliar/caule + bainha de aveia-preta e triticale nos sistemas de corte e de pastejo. Revista Brasileira de Zootecnia, v. 36, n. 5, p. 1512-1517, 2007.

FLARESSO, J. A.; GROSS, C. D.; ALMEIDA, E. X. Época e Densidade de Semeadura de aveia preta (Avena strigosa Schreb.) e azevém (Lolium multiflorum Lam.) no Alto Vale do Itajaí, Santa Catarina. Revista Brasileira de Zootecnia, v. 30, n. 6, p. 1969-1974, 2001.

FLORES, R. A. et al. Produção de forragem de populacões de azevém anual no estado do Rio Grande do Sul. Revista Brasileira de Zootecnia, v. 37, n. 7, p. 1168-1175, 2008.

FONTANELI, R. S. et al. Rendimento e valor nutritivo de cereais de inverno de duplo propósito: forragem verde e silagem ou grãos. Revista Brasileira de Zootecnia, v. 38, n. 11, p. 2116-2120, 2009.

INSTITUTO AGRONÔMICO DO PARANÁ. Cartas climáticas do Paraná. Disponível em: <http://www.iapar.br/modules/ conteudo/conteudo.php?conteudo=615>. Acesso em: 19 dez. 2009.

KIRCHNER, R. et al. Desempenho de forrageiras hibernais sob distintos níveis de luminosidade. Revista Brasileira de Zootecnia, v. 38, n. 11, p. 2371-2378, 2010.

MAACK, R. Geografia física do Estado do Paraná. Curitiba, 1968. 350 p.
MORAES, Y. J. B. Forrageiras. Conceitos, formação e manejo. Guaíba: Livraria e Editora Agropecuária, 1995. 215 p.

NELSON, L. R.; PHILLIPS, T. D.; WATSON, C. E. Plant breeding for improved production in annual ryegrass. In: ROUQUETTE, F. M.; NELSON, L. R. (Ed.) Ecology, production, and management of Lolium for forage in the USA. Madison: Crop Science Society of América, 1995. 125 p.

NICOLOSO, R. S.; LANZANOVA, M. E.; LOVATO, T. Manejo das pastagens de inverno e potencial produtivo de sistemas de integração lavoura-pecuária no Estado do Rio Grande do Sul. Ciência Rural, v. 36, n. 6, p. 1799-1805, 2006.

PEREIRA,V. A. et al. Comportamento agronômico de populações de azevém anual (Lolium multiflorum L. ) para cultivo invernal na região sudeste. Ciência Agrotécnica, v. 32, n. 2, p. 567-572, 2008.

PIN, E. A. et al. Forage production dynamics of winter annual grasses sown on different dates. Revista Brasileira de Zootecnia, v. 40, n. 3, p. 509-517, 2011.

ROSSETO, C. A. V.; NAKAGAVA, L. Época de colheita e desenvolvimento vegetativo de aveia-preta. Scientia Agrícola, v. 58, n. 4, p. 731-736, 2001.

SÁ, J. P. G. Utilização da aveia na alimentação animal. Londrina: Instituto Agronômico do Paraná. 1995. 20 p.

SILVA, S. C. da; NASCIMENTO JÚNIOR, D. Ecofisiologia de plantas forrageiras. In: SIMPÓSIO SOBRE MANEJO ESTRATÉGICO DA PASTAGEM, 3., 2006, Viçosa. Anais... Viçosa: UFV, 2006. p. 1-42.

SODRÉ FILHO, J. et al. Fitomassa e cobertura do solo de culturas de sucessão ao milho na Região do Cerrado. Pesquisa Agropecuária Brasileira, v. 39, n. 4, p. 327-334, 2004.

VARGAS, de C. R. C. J. et al. Dissimilaridade genética entre populações de azevém anual no Rio Grande do Sul. Revista Brasileira Agrociência, v. 12, n. 2, p. 133-138, 2006. 